\title{
Facial palsy: what can the multidisciplinary team do?
}

\author{
Daniel P Butler \\ Adriaan $O$ Grobbelaar \\ Department of Plastic and \\ Reconstructive Surgery, Royal Free \\ Hospital, London, UK
}

This article was published in the following Dove Press journal: Journal of Multidisciplinary Healthcare 25 September 2017

Number of times this article has been viewed
Correspondence: Daniel P Butler Department of Plastic and Reconstructive Surgery, Royal Free Hospital, Pond Street, London NW3 2QG, UK Tel +442077940500 Email danielbutler@nhs.net

\begin{abstract}
The functional and psychosocial impact of facial paralysis on the patient is significant. In response, a broad spectrum of treatment options exist and are provided by a multitude of health care practitioners. The cause and duration of the facial weakness can vary widely and the optimal care pathway varies. To optimize patient outcome, those involved in the care of patients with facial palsy should collaborate within comprehensive multidisciplinary teams (MDTs). At an international level, those involved in the care of patients with facial paralysis should aim to create standardized guidelines on which outcome domains matter most to patients to aid the identification of high quality care. This review summarizes the causes and treatment options for facial paralysis and discusses the subsequent importance of multidisciplinary care in the management of patients with this condition. Further discussion is given to the extended role of the MDT in determining what constitutes quality in facial palsy care to aid the creation of accepted care pathways and delineate best practice.
\end{abstract}

Keywords: facial palsy, multidisciplinary, outcome

\section{Introduction}

Facial palsy is characterized by weakness of the mimetic facial musculature. The potential spectrum of paralysis can range from a single, unilateral facial region being affected to a dense, bilateral facial paralysis characterized by a complete loss of dynamic facial expression. The majority of cases of facial paralysis are acquired with an estimated incidence of 118,000 cases in the USA per annum. ${ }^{1}$

The focus of pathology centers on the facial nerve (cranial nerve VII). As such, a myriad of additional end organs can be affected according to the location of the lesion along the length of the facial nerve. A proximal facial nerve lesion, for example, can result in ipsilateral hyperacusis, altered taste sensation in the anterior two-thirds of the tongue, and keratoconjunctivitis sicca.

An additional factor in determining a patient's symptoms and long-term outcome relates to the varying potential for facial nerve recovery. Facial paralysis can arise from a broad spectrum of different etiologies, each with their own potential for spontaneous reneurotization. ${ }^{2-4}$ Furthermore, additional patient morbidity can arise from mimetic muscle reinnvervation. Both synkinesis (involuntary movements accompanying voluntary movements) and hyperkinesis (muscle tightness and hypertonia) can occur when the facial nerve regenerates in an aberrant manner. ${ }^{5-7}$

Consequent to the extensive etiological base of facial paralysis, patients can present for their primary review to a multitude of different health care professionals. These 
include primary care physicians, neurologists, pediatricians, otolaryngologists, ophthalmologists maxillofacial, or plastic and reconstructive surgeons. Despite this, each patient requires comprehensive care from a broad range of health care professionals to optimize their appearance, functional, and psychosocial outcomes. ${ }^{8}$ An effective facial palsy multidisciplinary team (MDT) should be equipped to provide the full breadth of patient care that considers the cause and potential longevity of the condition.

\section{Facial palsy management overview}

The need for multidisciplinary care in the management of patients with facial palsy centers on the spectrum of invasive and noninvasive interventions available. In addition, the etiology and chronicity of the facial nerve dysfunction determine which treatment options are appropriate.

Invasive options include surgical procedures that support the facial soft tissues (static) or those that reanimate facial movements (dynamic) along with procedures designed to paralyze parts of the unaffected side of the face to restore symmetry. Direct repair of the facial nerve was first reported in the year $1821 .{ }^{9,10}$ From this point, an increasing understanding of the capacity for neural regeneration following injury, along with the use of nerve grafts and transfers created the potential for reinnervating native facial musculature with the potential to function. ${ }^{11-13}$ These procedures were, however, unsuitable in those whose facial musculature had been dennervated for a more prolonged period of time and showed little activity on neurophysiological testing. ${ }^{14}$ At this stage, degeneration of the neuromuscular junction has occurred and an irreversible process of atrophy and fibrosis renders the native facial musculature nonfunctional. In these situations, dynamic reanimation of the face can only be achieved through the introduction of functional muscle units into the affected regions of the face. ${ }^{15-17}$ In addition to those procedures designed to reanimate the facial movements, a large number of procedures exist to provide static support to the paralyzed areas. ${ }^{14}$ Furthermore, in cases where the facial paralysis is localized to a particular region of the face, or to supplement previous surgical attempts, contralateral chemodenervation of the healthy facial musculature is a common treatment option to improve facial symmetry. ${ }^{18}$

Noninvasive treatment options are an essential adjunct to the aforementioned invasive techniques. With Bell's palsy being the most common cause of facial paralysis and $70 \%$ of patients expected to return to normal facial function, noninvasive treatments are often the only intervention required. ${ }^{3}$ The early use of steroids in the management of Bell's palsy is well established and simple techniques for ocular protection, such as eye taping at night and lubricating drops, would usually be commenced by a primary care physician. ${ }^{19,20}$ In those with more established facial paralysis, a spectrum of facial rehabilitation interventions exist with ongoing debate on their effectiveness as an isolated treatment. ${ }^{21,22}$ These range from stretching exercises and electrical stimulation through neuromuscular retraining. ${ }^{21,22}$

In addition to interventions that optimize the facial appearance and function, the psychosocial well-being of the patient must be considered. Facial expressions play a critical role in communicating emotions and affected individuals can be perceived as uninterested, unfriendly, or of lower intelligence. ${ }^{23}$ Furthermore, facial asymmetry can be extremely disfiguring, thus stigmatizing the patient in a social setting. ${ }^{24}$ In association with the disruption in psychosocial health, the prevalence of anxiety and depression in those with facial palsy is increased..$^{25}$

\section{Role of the MDT in facial palsy management}

Central to a multidisciplinary approach to health care is collaboration between different subspecialties. This allows for the development of a comprehensive management plan for the patient and is now widely accepted as an effective means to approach patient care. ${ }^{26}$ Multidisciplinary care is now well established for many different conditions such as oncology, ${ }^{27}$ diabetes, ${ }^{28}$ stroke, ${ }^{29}$ and burn care. ${ }^{30}$ This is based on the improved short- and long-term clinical outcomes ${ }^{31,32}$ and patient satisfaction. ${ }^{33}$ Despite these benefits, there remains inconclusive evidence that a multidisciplinary approach is cost-effective. ${ }^{34}$ This systematic review ${ }^{34}$ is, however, focused upon oncology-focused MDTs, where there will be significant organizational and managerial costs relating to collation of the necessary medical records to facilitate discussion. Furthermore, costing outcomes such as patient satisfaction and function is very challenging in comparison to clearly defined outcome measures such as disease-free survival. ${ }^{34}$ It is the former outcome domains that are most relevant to a facial palsy population, which would make evaluation of the cost-effectiveness of multidisciplinary care within this population challenging.

To provide holistic patient care to those affected by facial paralysis, high-volume units have established MDTs with the full breadth of expertise. Within our department, the core facial palsy MDT is led by a facial plastic surgeon who acts as the principal coordinator of the patient's care. This role entails detailed primary evaluation of the patient 
at first review, coordinating the time frame for any interventions planned and ensuring the engagement and interaction of all members of the MDT. The additional members of the MDT include an oculoplastic surgeon, maxillofacial surgeon, physical therapist, speech therapist, psychologist, and medical photographer to offer the full repertoire of interventions previously discussed. Each new patient is reviewed in a bimonthly combined clinic with all members of the MDT present and then subsequent consultations are conducted by the necessary team members with the facial plastic surgeon overseeing the ongoing care pathway.

An MDT setup not only ensures that the patient has early access to the full repertoire of care but also serves to reduce the time accrued from ongoing patient referral. ${ }^{35}$ In cases of acquired facial palsy with minimal potential for spontaneous recovery, early surgical review can facilitate the introduction of treatment solutions that preserve the function of the native musculature. Such a step can significantly improve the resulting functional outcomes of the patient. ${ }^{8}$ Nonintegrated care can delay review by a suitable service and commit the patient to less-desirable interventions, such as free functional muscle transfer or static soft tissue support. Despite the proposed benefits, ${ }^{36-40}$ it should be noted that no objective studies have been performed to demonstrate that integrated, multidisciplinary care improves the long-term outcome of patients with facial palsy.

In addition to establishing the benefit of multidisciplinary care in the management of facial palsy, a further challenge facing the facial palsy MDT involves greater integration with primary care. The medical system in the UK involves patients presenting to their general practitioner in the first instance who will then introduce appropriate treatment and determine the need for referral to secondary care. This creates opportunity for delay in the referral of those who would benefit from early MDT input. Given the incidence of facial palsy, however, early referral of all patients with facial paralysis would create excessive burden on the resources of secondary care teams. ${ }^{41}$ Instead, the MDT should endeavor to produce appropriate guidance on referral pathways for clinicians ${ }^{42}$ and exploit increasing patient engagement with the Internet by creating online educational material to empower patients in their care. ${ }^{43}$

\section{Multidisciplinary collaboration in outcome measurement}

Alongside direct patient care, health care professionals in the field of facial palsy must collaborate at an international level to advance patient care. The central focus of this collaborative process should be to determine which measures best determine the outcome attained by the patient. Monitoring outcomes allows evaluation of different treatments, providers, and even health care systems. It is, however, essential that outcome domains and measurement tools are chosen that offer a valid reflection of the outcome as perceived by the patient.

Recording patient outcomes is a central component of value-based health care as proposed by Porter. ${ }^{44}$ Optimizing patient outcome acts as a treatment objective that unifies the concerns of all stakeholders involved in patient care. Porter argues that "value is defined as the health outcomes achieved per dollar spent". ${ }^{44}$ As such, resources can be focused upon the interventions that deliver greatest patient value.

In addition to improved value, outcome measurement allows greater comparison between treating units to identify those that can act as the benchmark for high-quality care. Others can then aim to replicate this care model in their respective institutions. A further benefit in standardizing outcome measurements is to improve the consistency in reporting clinical research outcomes. This would expedite the adoption of effective interventions.

The first stage in moving toward an outcome-centric approach in facial palsy care is to determine the outcome domains that matter most to patients. To address this aim, organizations such as the International Consortium for Health Outcome Measurements (ICHOM) have been created. ICHOM is a not-for-profit organization established by Harvard University Institute for Strategy and Competitiveness, Boston Consulting Group, and the Karolinska Institute. A multidisciplinary, collaborative approach between health care professionals and patient representatives has been adopted by ICHOM. ${ }^{45}$ Through this approach, key outcome domains are identified and appropriate measurement tools selected. The inclusion of patient representatives ensures that the outcome domains chosen by the health care professionals are those that matter most to patients. A number of standardized outcome measurement sets have been created using this approach. ${ }^{46-48}$ Currently, an ICHOM-led program to standardize the outcome measurements in pediatric facial palsy care is underway. ${ }^{49}$

Following creation of a standardized facial palsy outcome measurement set, the MDT will have an important role in implementing the collection of the relevant data. This phase is likely to present a number of challenges in relation to the additional administrative burden arising from comprehensive outcome measurement. Once routine data collection is established throughout centers treating patients with facial 
palsy, cross-collaboration and comparison will be essential to improve patient care. Holistic outcome measurement that focuses on the end point of patient care rather than each individual intervention is likely to reward greater multidisciplinary working.

\section{Conclusion}

Facial palsy carries a significant functional and psychosocial burden. The etiological basis for facial paralysis is extensive and, as such, patients may present for primary review to a broad spectrum of health care professionals. Optimal care is, therefore, best delivered in a multidisciplinary capacity to ensure that the health care professionals collaborate to offer patients the full repertoire of treatment options at a time that best optimizes patient outcome. Facial palsy MDTs must also engage at an international level to determine what constitutes quality in the care of facial paralysis. From this, effective care pathways can be delineated and greater value delivered to the patient.

\section{Disclosure}

The authors are members of the working group for the International Consortium of Health Outcomes Measurement (ICHOM) program for developing standardization in outcome measurement among pediatric patients with facial palsy. The authors report no other conflicts of interest in this work.

\section{References}

1. Bleicher JN, Hamiel S, Gengler JS, Antimarino J. A survey of facial paralysis: etiology and incidence. Ear Nose Throat J. 1996; 75(6):355-358.

2. Hohman MH, Hadlock TA. Etiology, diagnosis and management of facial palsy: 2000 patients at a Facial Nerve Centre. Laryngoscope. 2014;124:e283-e293.

3. Peitersen E. Bell's palsy: the spontaneous course of 2,500 peripheral facial nerve palsies of different etiologies. Acta Otolaryngol Suppl. 2002;549:4-30.

4. Adour KK, Byl FM, Hilsinger RL Jr, et al. The true nature of Bell's palsy: analysis of 1,000 consecutive patients. Laryngoscope. 1978;88:787-801.

5. Crumley RL. Mechanisms of synkinesis. Laryngoscope. 1979;89(11): 1847.

6. Salles AG, da Costa EF, Ferreira MC, Remigio AF, Moraes LB, Gemperli R. Epidemiologic overview of synkinesis in 353 patients with longstanding facial paralysis under treatment with botulinum toxin for 11 years. Plast Reconstr Surg. 2015;136(6):1289-1298.

7. Filipo R, Spahiu I, Covelli E, Nicastri M, Bertoli GA. Botulinum toxin in the treatment of facial synkinesis and hyperkinesis. Laryngoscope. 2012;122:266-270.

8. Hadlock TA, Greenfield LJ, Wernick-Robinson M, Cheney ML. Multimodality approach to management of the paralyzed face. Laryngoscope. 2006;116(8):1385-1389.

9. Sajadi MM, Sajadi MR, Tabatabaie SM. The history of facial palsy and spasm: Hippocrates to Razi. Neurology. 2011;77(2):174-178.
10. Bell C. On the nerves, giving an account of some experiments on their structure and functions, which leads to a new arrangement of the system. Trans R Soc Lond. 1821;3:398.

11. Scaramella LF. Cross-face facial nerve anastomosis: historical notes. Ear Nose Throat J. 1996;75(6):343-354.

12. Endo T, Hata J, Nakayama Y. Variations on the "baby-sitter" procedure for reconstruction of facial paralysis. J Reconstr Microsurg. 2000; $16: 37-43$.

13. Terzis JK, Tzafetta K. The "babysitter" procedure: minihypoglossal to facial nerve transfer and cross-facial nerve grafting. Plast Reconstr Surg. 2009;123:865-876.

14. Rovak JM, Tung TH, Mackinnon SE. The surgical management of facial nerve injury. Semin Plast Surg. 2004;18(1):23-30.

15. Harii K, Ohmori K, Torii S. Free gracilis muscle transplantation with microneurovascular anastomoses for the treatment of facial paralysis. A preliminary report. Plast Reconstr Surg. 1976;57(2):133-143.

16. Nduka C, Hallam MJ, Labbe D. Refinements in smile reanimation: 10-year experience with the lengthening temporalis myoplasty. J Plast Reconstr Aesthet Surg. 2012;65(7):851-856.

17. Harrison DH, Grobbelaar AO. Pectoralis minor muscle transfer for unilateral facial palsy reanimation: an experience of 35 years and 637 cases. J Plast Reconstr Aesthet Surg. 2012;65(7):845-850.

18. Mehdizadeh OB, Diels J, White WM. Botulinum toxin in the treatment of facial paralysis. Facial Plast Surg Clin North Am. 2016;24(1):11-20.

19. Jowett N, Hadlock TA. Contemporary management of Bell palsy. Facial Plast Surg. 2015;31(2):93-102.

20. Hato N, Yamada H, Kohno H, et al. Valacyclovir and prednisolone treatment for Bell's palsy: a multicenter, randomized, placebo-controlled study. Otol Neurotol. 2007;28:408-413.

21. Lindsay RW, Robinson M, Hadlock TA. Comprehensive facial rehabilitation improves function in people with facial paralysis: a 5-year experience at the Massachusetts Eye and Ear Infirmary. Phys Ther. 2010;90(3):391-397.

22. Teixeira LJ, Soares BG, Vieira VP, Prado GF. Physical therapy for Bell's palsy (idiopathic facial paralysis). Cochrane Database Syst Rev. 2008;3:CD006283.

23. Bogart KR, Tickle-Degnen L, Ambady N. Compensatory expressive behavior for facial paralysis: adaptation to congenital or acquired disability. Rehabil Psychol. 2012;57(1):43-51.

24. Masnari O, Schiestl C, Rössler J, et al. Stigmatization predicts psychological adjustment and quality of life in children and adolescents with a facial difference. J Pediatr Psychol. 2013;38(2):162-172.

25. VanSwearingen JM, Cohn JF, Bajaj-Luthra A. Specific impairment of smiling increases the severity of depressive symptoms in patients with facial neuromuscular disorders. Aesthetic Plast Surg. 1999;23(6):416-423.

26. Baker DP, Day R, Salas E. Teamwork as an essential component of high reliability organizations. Health Serv Res. 2006;41:1576-1598.

27. Tripathy D. Multidisciplinary care for breast cancer: barriers and solutions. Breast J. 2003;9(1):60-63.

28. Powell PW, Corathers SD, Raymond J, Streisand R. New approaches to providing individualized diabetes care in the 21 st century. Curr Diabetes Rev. 2015;11(4):222-230.

29. Clarke DJ, Forster A. Improving post-stroke recovery: the role of the multidisciplinary health care team. J Multidiscip Healthc. 2015;8:433-442.

30. Butler DP. The 21st century burn care team. Burns. 2013;39(3):375-379.

31. Stroke Unit Trialists' Collaboration. Organised inpatient (stroke unit) care for stroke. Cochrane Database Syst Rev. 2013;9:[ArtNo:CD000197].

32. Kesson EM, Allardice GM, George WD, Burns HJ, Morrison DS. Effects of multidisciplinary team working on breast cancer survival: retrospective, comparative, interventional cohort study of 13722 women. BMJ. 2012;344:e2718.

33. Boxer MM, Vinod SK, Shafiq J, Duggan KJ. Do multidisciplinary team meetings make a difference in the management of lung cancer? Cancer. 2011;117(22):5112-5120. 
34. Ke KM, Blazeby JM, Strong S, Carroll FE, Ness AR, Hollingworth W. Are multidisciplinary teams in secondary care cost-effective? A systematic review of the literature. Cost Eff Resour Alloc. 2013;11(1):7.

35. Reeves S, Lewin S, Espin S, Zwarenstein M. Interprofessional Teamwork for Health and Social Care. Chichester: Wiley Blackwell; 2010.

36. Gaudin RA, Jowett N, Banks CA, Knox CJ, Hadlock TA. Bilateral facial paralysis: a 13-year experience. Plast Reconstr Surg. 2016;138(4):879-887.

37. Pedersen LK, Maimburg RD, Hertz JM. Moebius sequence - a multidisciplinary clinical approach. Orphanet J Rare Dis. 2017;12(1):4.

38. McKay VH, Touil LL, Jenkins D, Fattah AY. Managing the child with a diagnosis of Moebius syndrome: more than meets the eye. Arch Dis Child. 2016;101(9):843-846.

39. Sharma PR, Zuker RM, Borschel GH. Perspectives in the reconstruction of paediatric facial paralysis. Curr Opin Otolaryngol Head Neck Surg. 2015;23(6):470-479.

40. Eviston TJ, Croxson GR, Kennedy PG, Hadlock T, Krishnan AV. Bell's palsy: aetiology, clinical features and multidisciplinary care. J Neurol Neurosurg Psychiatry. 2015;86(12):1356-1361.

41. De Diego JI, Prim MP, Madero R, Gavilán J. Seasonal patterns of idiopathic facial paralysis: a 16-year study. Otolaryngol Head Neck Surg. 1999;120(2):269-271.

42. Nice.org.uk. National Institute for Health and Clinical Excellence; c2016. Available from: https://cks.nice.org.uk/bells-palsy. Accessed January 2, 2017
43. Facialpalsy.org.uk [homepage on the Internet]. Facial Palsy UK; c2017. Available from: http://www.facialpalsy.org.uk/. Accessed January 2, 2017.

44. Porter ME. What is value in healthcare? N Engl J Med. 2010;363: 2477-2481.

45. Ichom.org [webpage on the Internet]. International Consortium for Health Outcome Measurements; c2016. Available from: http://www. ichom.org/who-we-are/. Accessed January 15, 2017

46. Ong WL, Schouwenburg MG, van Bommel AC, et al. A standard set of value-based patient-centered outcomes for breast cancer: The International Consortium for Health Outcomes Measurement (ICHOM) Initiative. JAMA Oncol. 2017;3(5):677-685.

47. Mak KS, van Bommel AC, Stowell C, et al; Lung Cancer Working Group of ICHOM. Defining a standard set of patient-centred outcomes for lung cancer. Eur Respir J. 2016;48(3):852-860.

48. Clement RC, Welander A, Stowell C, et al. A proposed set of metrics for standardized outcome reporting in the management of low back pain. Acta Orthop. 2015;86(5):523-533.

49. Ichom.org [webpage on the Internet]. Facial Palsy; c2016. Available from: http://www.ichom.org/medical-conditions/facial-palsy/. Accessed January 15, 2017.
Journal of Multidisciplinary Healthcare

\section{Publish your work in this journal}

The Journal of Multidisciplinary Healthcare is an international, peerreviewed open-access journal that aims to represent and publish research in healthcare areas delivered by practitioners of different disciplines. This includes studies and reviews conducted by multidisciplinary teams as well as research which evaluates the results or conduct of such teams or health

\section{Dovepress}

care processes in general. The journal covers a very wide range of areas and welcomes submissions from practitioners at all levels, from all over the world. The manuscript management system is completely online and includes a very quick and fair peer-review system. Visit http://www.dovepress.com/ testimonials.php to read real quotes from published authors. 